\title{
X-ray spectral microanalysis of W-Ni-Fe pseudoalloy obtained from electroerosive powders
}

\author{
Evgeny V. Ageev ${ }^{1 *}$, Oxana G. Loktionova ${ }^{1}$, Sergey V. Pikalov ${ }^{1}$ and Valeryi I. Kolmykov ${ }^{1}$ \\ ${ }^{1}$ South-West state University, 305040, Kursk, Russia
}

\begin{abstract}
The results of X-ray spectral microanalysis of W-Ni-Fe pseudo-alloy, obtained from electroerosive powders, are presented. Consolidation of the obtained electroerosive powders was carried out by the method of spark plasma sintering using the SPS 25-10 spark plasma sintering system. Using an EDAX energy-dispersive X-ray analyzer built into a Quanta 600 FEG scanning electron microscope, characteristic X-ray spectra were obtained at various points on the sample surface and along a transverse section. As a result of the study, it was found that on the surface of the investigated sintered sample, tungsten, nickel and iron are contained as the main elements, and oxygen, copper and chromium are also present in small amounts.
\end{abstract}

\section{Introduction}

Pseudo-alloys W-Ni-Fe are widely used in industry, and as a result, there is a problem with the processing of their waste and reuse [1-8].

The existing technologies for the production of W-Ni-Fe alloys are characterized by large tonnage, energy intensity, large production areas, low productivity, and environmental problems. One of the main problems in the use of these alloys at the present time is waste processing and further use. Numerous attempts to remove tungsten from these alloys, due to its high cost, have not ended successfully, since none of the refractory compounds provides such high strength characteristics. Therefore, the problem of utilization of waste alloys W$\mathrm{Ni}$-Fe is currently very relevant.

One of the most promising methods of disposal of almost any electrically conductive material, including the W-Ni-Fe alloy, characterized by relatively low energy consumption and environmental friendliness of the process, is the method of electroerosive dispersion (EED) [9-11].

The relevance of the work is determined by the important economic task of creating progressive, environmentally friendly, energy-saving and waste-free technologies for producing powders, including nanoscale ones, and their practical application.

\footnotetext{
*Corresponding author: ageev_ev@mail.ru
} 
Complex theoretical and experimental studies are required to develop technologies for producing products from powders, obtained from W-Ni-Fe wastes and to assess the efficiency of their use. The EED method is one of the promising methods for producing powders from almost any conductive material, including from ball-bearing steel waste, and is characterized by relatively low energy consumption and environmental friendliness of the process [12-18].

Carrying out the planned measures will allow solving the problem of waste disposal and their further use and thereby reduce the cost of the final product.

\section{Materials and methods}

Waste (shavings) of the W-Ni-Fe alloy were selected to carry out the planned studies. Distilled water (GOST 6709-72) was chosen as the working liquid, since it has the simplest chemical composition, a sufficiently high cooling capacity, and also a relatively low cost.

To disperse the wastes of the alloy (chips) of the W-Ni-Fe alloy, an installation protected by RF Patent No. 2449859 was used. Dispersion modes were as follows: pulse repetition rate $100 \mathrm{~Hz}$; voltage $100 \mathrm{~V}$; the capacity of the discharge capacitors is $24 \mu \mathrm{F}$.

Scanning electron microscopy was used to study the microstructure of the sample (along the surface and along the transverse section). The surface (along the section) of the sample was ground and polished. Grinding was carried out with metallographic paper with coarse (No. 60-70) and fine grain (No. 220-240). During grinding, the sample was periodically rotated by $90^{\circ}$. The abrasive particles were washed off with water and subjected to polishing on a wheel with suspensions of metal oxides (Fe3O4, Cr2O3, Al2O3). After reaching a mirror finish, the surface of the section was washed with water, alcohol, and dried with filter paper. Using an EDAX energy-dispersive X-ray analyzer built into a Quanta 600 FEG scanning electron microscope, characteristic X-ray spectra were obtained at various points on the sample surface and along a transverse section.

Consolidation of the obtained electroerosive powders was carried out by the method of spark plasma sintering using a spark plasma sintering system SPS 25-10 (Thermal Technology, USA).

\section{Results and Discussion}

The location of the X-ray spectral microanalysis is shown in Figure 1.

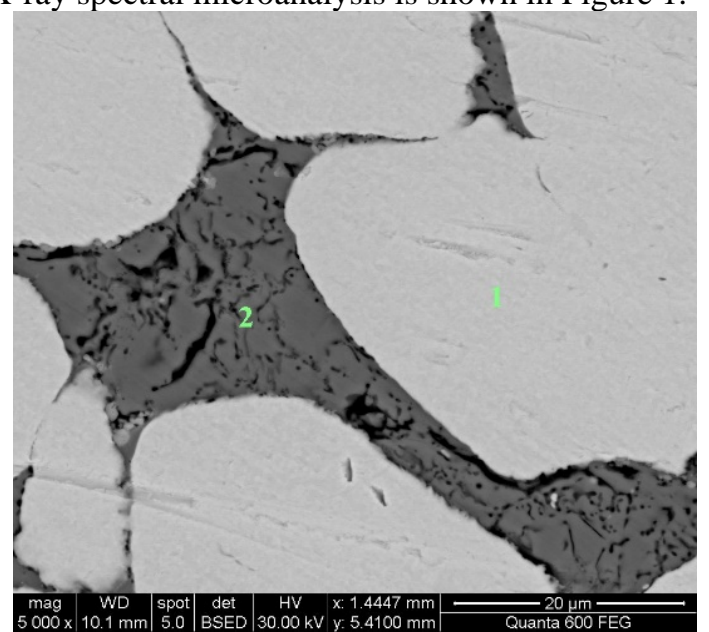

Fig. 1. X-ray spectral microanalysis location 
The elemental composition at point 1 is shown in Figure 2 and Table 1.

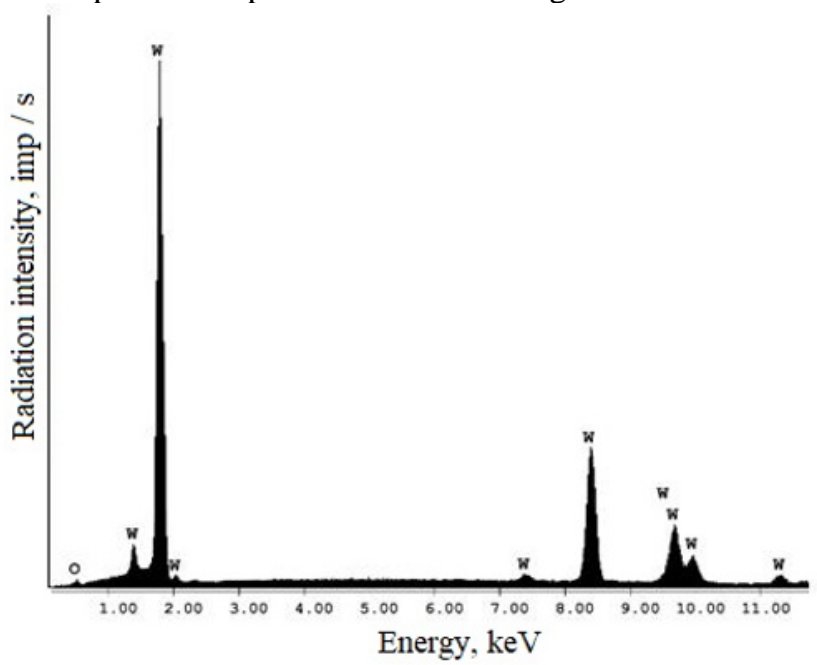

Fig. 2. Elemental composition at point 1

Table 1. Elemental composition of the sintered sample at point 1

\begin{tabular}{|c|c|c|}
\hline Element & Mass fraction, \% & Atomic fraction, $\%$ \\
\hline O & 1,41 & 14,12 \\
\hline W & 98,59 & 85,88 \\
\hline Total & 100,00 & 100,00 \\
\hline
\end{tabular}

As a result of the studies, it was found that on the surface of the investigated sintered sample at point 1 , tungsten is contained as the main element, and oxygen is also present in a small amount.

The elemental composition at point 2 is shown in Figure 3 and Table 2.

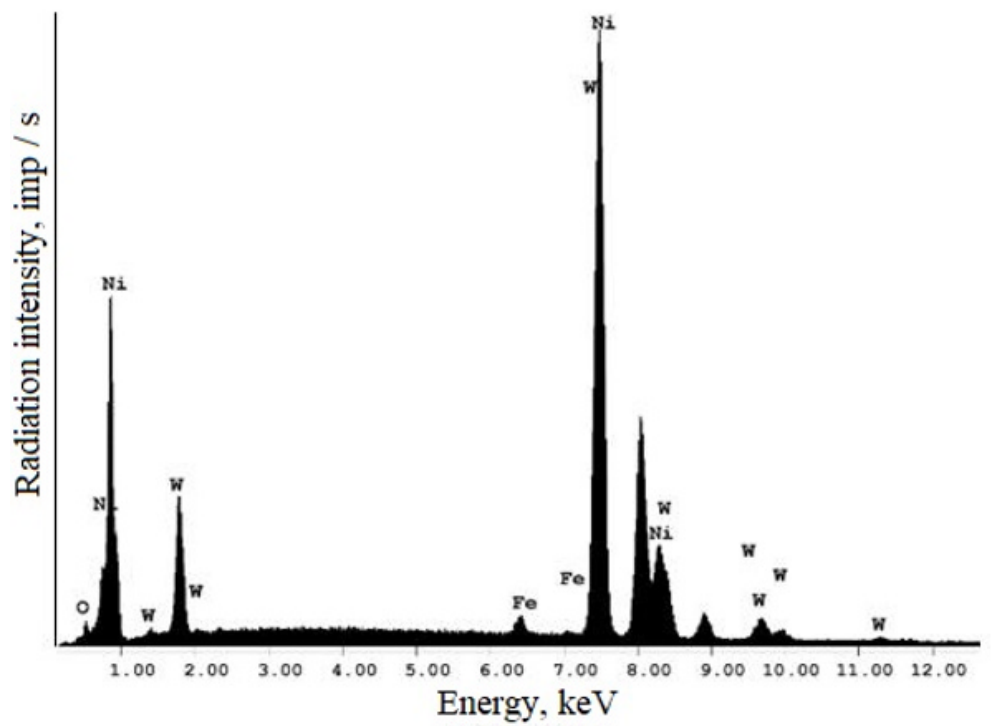

Fig. 3. Elemental composition at point 2 
Table 2. Elemental composition at point 2 of the sintered sample.

\begin{tabular}{|c|c|c|}
\hline Element & Mass fraction, $\%$ & Atomic fraction, $\%$ \\
\hline $\mathrm{O}$ & 2,57 & 10,44 \\
\hline $\mathrm{Fe}$ & 1,14 & 1,63 \\
\hline $\mathrm{Ni}$ & 71,48 & 79,24 \\
\hline $\mathrm{W}$ & 24,56 & 8,69 \\
\hline Total & 100,00 & 100,00 \\
\hline
\end{tabular}

As a result of the studies, it was found that on the surface of the sintered sample under study at point 2, tungsten, nickel and iron are contained as the main elements, and oxygen is also present in a small amount.

As a result of the study, it was found that on the surface of the investigated sintered sample, tungsten, nickel and iron are contained as the main elements, and oxygen, copper and chromium are also present in small amounts.

The experiment showed that the average particle size is 23.86 microns.

\section{Conclusion}

Carrying out the planned measures will allow to solve the problem of waste disposal of W$\mathrm{Ni}-\mathrm{Fe}$ alloys and their further use and thereby reduce the cost of the final product.

This work was supported by a grant from the President of the Russian Federation (NSh-2564.2020.8).

\section{References}

[1] Z. Qiao, X. Ma, W. Zhao, H. Tang, B. Zhao, Nanostructured novel cemented hard alloy obtained by mechanical alloying and hot-pressing sintering and its applications, Journal of Alloys and Compounds. 2008. vol. 462. No. 1-2. pp. 416-420.

[2] S.S. Nayak, S.K. Pabi, M. Wollgarten, J. Banhart, B.S. Murty, Nanocomposites and an extremely hard nanocrystalline intermetallic of al-fe alloys prepared by mechanical alloying, Materials Science and Engineering: A, 2010, vol. 527, No. 9, pp. 2370-2378.A.A. Lipatov, Reactive diffusion in cutting high-alloy steel by means of a hard-alloy tool, Russian Engineering Research, 2013, vol. 33, No. 3, pp. 144149.

[3] A.M. Adaskin, A.A. Vereshchaka, A.S. Vereshchaka, Study of wear mechanism of hard-alloy tools during machining of refractory alloys, Journal of Friction and Wear, 2013, vol. 34, No. 3, pp. 208-213.

[4] V.L. Bibik, Forecasting of hard-alloyed cutting tool resistance based on thermal diffusivity, Materials Science Forum, 2013, vol. 762, pp. 777-781.

[5] E.V. Azarova, E.A. Levashov, V.G. Ralchenko, A.P. Bolshakov, E.E. Ashkinazi, Creation of strong adhesive diamond coatings on hard alloy by electric-spark alloying, Metallurgist, 2010, vol. 54, № 7-8, pp. 523-529.

[6] K. Maruyama, T. Nonaka, H.Y. Kim, Effects of $\alpha 2$ spacing on creep deformation characteristics of hard oriented pst crystals of tial alloy, Intermetallics, 2005, vol. 13, No. 10, pp. 1116-1121.

[7] A. Shenhar, I. Gotman, S. Radin, P. Ducheyne, Microstructure and fretting behavior of hard tin-based coatings on surgical titanium alloys, Ceramics International, 2000, T. 26, No. 7, pp. 709-713. 
[8] E.V. Ageev, A.S. Osminina, E.V. Ageeva, Properties and Characterizations of Powders Produced from Waste Carbides, Journal of nano- and electronic physics, 2013, vol. 5, No. 4, pp. 04038-1-04038-2.

[9] Ageev, A.V. Kirichek, A.Yu. Altuhov, E.V. Ageeva, Hard alloy synthesis from tungsten-containing electroerosion powders of micro- and nanometric fractions, Journal of nano- and electronic physics, 2014, vol. 3, pp. 03001-1-03001-4.

[10] E.V. Ageev, R.A. Latypov, Fabrication and investigation of carbide billets from powders prepared by electroerosive dispersion of tungsten-containing wastes, Russian Journal of Non-Ferrous Metals, 2014, vol. 55, No. 6, pp. 577-580.

[11] E.V. Ageeva, E.V. Ageev, N.M. Horyakova, Morphology of copper powder produced by electrospark dispersion from waste, Russian Engineering Research, 2014, vol. 34, No. 11, pp. 694-696.

[12] E.V. Ageeva, E.V. Ageev, N.M. Horyakova, Morphology and composition of copper electrospark powder suitable for sintering, Russian Engineering Research, 2015, vol. 35, No. 1, pp. 33-35.

[13] E.V. Ageev, R.A. Latypov, E.V. Ageeva, Investigation into the properties of electroerosive powders and hard alloy fabricated from them by isostatic pressing and sintering, Russian Journal of Non-Ferrous Metals, 2015, vol. 56, No. 1, pp. 52-62.

[14] E.V. Ageeva, I.A. Avilova, N.M. Horyakova, Preparation of Copper Electroerosion Nanopowders from Waste of Aquatic Medium and its Validation by Physicochemical Methods, Applied Mechanics and Materials, 2015, vol. 770, No. 1, pp. 23-27.

[15] E.V. Ageeva, E.V. Ageev, S.V. Pikalov, E.A. Vorobiev, A.N. Novikov, X-ray Analisis of the Powder of Micro- and Nanometer Fractions, Obtained from Wastes of Alloy T15K6 in Aqueous Medium, Journal of nano- and electronic physics, 2015, vol. 7, No. 4, Part 2, P. 04058(2).

[16] E.V. Ageeva, A.Yu. Altukhov, S.V. Khardikov, S.S. Gulidin , A.N. Novikov, Electroerosive Powder Obtained from Alloy VK8 Waste into Butanol, Journal of nano- and electronic physics, 2015, vol. 7, No. 4, Part 2, P. 04080(3).

[17] Ageeva, E. V. Installation for production of powder materials suitable for technological processes of restoration and strengthening of details / Ageeva E. V., Zubarev M. A. / works of GOSNITI. - Moscow: all-Russian research technological Institute of repair and operation of machine-truck, 2017 - №129. - P. 169-173.

[18] Ageev, E. V. analysis of the characteristics of wear resistance of nanocomposite coatings obtained using electroerosion materials / Ageev E. V., Pickalov V. S., Khardikov S. V., Zubarev M. A. // proceedings of the SWSU. - Kursk: SWSU, 2016 - №6 (69). - P. 40-49. 